\title{
Erratum to: Ethical and Surgical Dilemmas in Patients with Neglected Surgical Diseases Visiting a Field Hospital in a Zone of Recent Disaster
}

\author{
Guy $\operatorname{Lin}^{1} \cdot$ Tal Marom² ${ }^{2}$ David Dagan ${ }^{3} \cdot$ Ofer Merin $^{4}$
}

Published online: 8 September 2016

(C) Société Internationale de Chirurgie 2016

\section{Erratum to: World J Surg \\ DOI 10.1007/s00268-016-3692-x}

In the initial online publication, Ofer Merin's family name and given name were interchanged. The name has been corrected in the publication as shown in this erratum.

The online version of the original article can be found under doi:10.1007/s00268-016-3692-x.

\section{Guy Lin}

ofralin@gmail.com

1 The Surgical Division, Kaplan Medical Center, Rehovot, Israel

2 Department of Otolaryngology, Assaf Harofeh Medical Center, Zerifin, Israel

3 Office of the Surgeon General, The Israel Defense Forces, Tel Hashomer, Israel

4 The Trauma Unit, Shaare Zedek Medical Center, Jerusalem, Israel 